\title{
Hypolipidemic effect and activation of Lecithin Cholesterol Acyl Transferase (LCAT) by aqueous extract of Spirulina platensis during toxicological investigation
}

Vicky Jocelyne Ama Moor ${ }^{1 *}$, Prosper Cabral Nya Biapa², Borgia Legrand Nono Njinkio³, Bruno Moukette Moukette ${ }^{1}$, Zacharie Sando ${ }^{1}$, Cyril Kenfack ${ }^{4}$, Baruch Ateba ${ }^{4}$, Marthe Elise Ngo Matip ${ }^{5}$, Constant Anatole Pieme ${ }^{1}$ and Jeanne Ngogang ${ }^{1}$

\begin{abstract}
Background: Spirulina platensis produced in Nomayos (Cameroon) is used as a dietary supplement. S. platensis is known as a neutraceutical with many beneficial effects on humans like lipid-lowering action. This study aims to investigate the mechanism of hypolipidemic action of aqueous extract of Spirulina platensis (S. platensis) through the toxicological studies.

Methods: In this study, we included two month old Wistar rats, weighing between 180 and $200 \mathrm{~g}$. Aqueous S. platensis was extracted and prepared using standard methods. The rats received a supplementation of S. platensis at $5000 \mathrm{mg} / \mathrm{Kg}$ of body weight as single dose in acute toxicity whereas different doses $(250,500,1000 \mathrm{mg} / \mathrm{kg}$ body weight) were administered in subacute toxicity compared to control. Acute and subacute toxicities were determined according to the guidelines 420 (14 days) and 407 (28 days) of the Organization for Economic Cooperation and Development (OECD) respectively. Biochemical parameters such as urea, creatinine, total and direct bilirubin, lipid profile and transaminases; and histopathological analysis of the liver and kidneys were used to evaluate the toxicity of S. platensis on these Wistar rats. Plasmatic hydroxymethyl glutaryl coenzyme A reductase (HMG CoA reductase) and lecithine cholesterol acyl transferase (LCAT) were performed to explain the lipid-lowering action of S. platensis. Histopathological analysis of the liver and kidneys was performed.

Results: Our results show a decrease in total cholesterol for male rats (from 84 to $74 \mathrm{mg} / \mathrm{dl}$ ) when the dose of S. platensis increased; this reduction of the total cholesterol level in male rats was significant at $500 \mathrm{mg} / \mathrm{kg}$. There was also a significant inhibition of HMG CoA reductase in a dose dependent manner between 25 and 84.5 fold compared to the control in both male and female groups. At the dose of $250 \mathrm{mg} / \mathrm{kg} \mathrm{bw}$, the level of LCAT was higher compared with other groups and control, but the difference was not statistically significant. A slight inflammation in the liver and the mesangial hyperplasia of the renal glomeruli was revealed by the histopathological investigation in subacute toxicity.
\end{abstract}

Conclusion: Spirulina platensis from Cameroon appears to have little toxic effects and may demonstrate hypolipidemic activity through the activation of LCAT.

Keywords: Spirulina platensis, Lipid profile, LCAT, HMG CoA reductase, Histopathology

\footnotetext{
* Correspondence: movicky@yahoo.fr

'Department Physiological Sciences and Biochemistry, Faculty of Medicine

and Biomedical Sciences - University of Yaounde 1, Yaounde, Cameroon

Full list of author information is available at the end of the article
} 


\section{Background}

Spirulina is a cyanobacteria belonging to the class of Cyanophyceae, Order of Oscillatoriaceae. It is also called Arthrospira, with photosynthetic effects [1]. There are several species of spirulina but the most consumed species by men remains Spirulina platensis (S. platensis) also called Arthrospira platensis. S. platensis naturally grows in high-salt alkaline water reservoirs in subtropical and tropical areas like America, Mexico, Asian and Central Africa $[2,3] . S$. platensis is a neutraceutical with many beneficial effects on humans such as antiviral, immunomodulation, immunostimulant, anti-inflammatory, hepatoprotective, anti-cancer, antioxidant and lipid-lowering [4-8].

The hypolipidemic effect of S.platensis or its extracts has been demonstrated in various animal models including mouse, rat, hamster and rabbit [9]. The cholesterol lowering activity of $S$. platensis was first reported in albino rats [10], followed by mice [11].

Hyperlipidemia is the presence of high, or abnormal levels of lipids and/or lipoproteins in the blood. There is a correlation between coronary diseases and high levels of lipoprotein [12].

Cardiovascular disease is a major cause of death in developed countries and high cholesterol is an important risk factor in atherosclerosis. Administration of S. platensis to volunteer males demonstrated, that although there was no significant increase in high- density lipoprotein (HDL) levels, a significant reduction of Low-density lipoprotein (LDL) cholesterol was noted after 8 weeks [13].

Other research describing the effects of $S$. platensis supplements on patients with ischemic heart disease found a significant reduction in blood cholesterol, triglycerides and LDL cholesterol and an increase in HDL cholesterol [14].

Recently in Cameroon, Ngo-Matip and al showed a reduction of cholesterol and an increased HDL among people living with HIV who consumed S. platensis [15]. Nevertheless, since dyslipidemias are a major cause of atherosclerosis, drugs such as statins and even certain herbs are used to lower cholesterol levels. The cholesterol-lowering effect of statins is due to the decrease in the biosynthesis of cholesterol by inhibition of the enzyme 3-hydroxy-3-methylglutaryl coenzyme A reductase (HMG CoA reductase). Some studies have also reported the ex vivo inhibition of HMG CoA reductase activity by herbs such as, Quercus infectoria, Rosa damascene, Myrtus communis, Andrographis paniculata, Anthocephalus indicus, and Ocimum sanctum $[16,17]$.

Recently therapeutic upregulation of lecithine cholesterol acyl transferase (LCAT) function has gained interest as a potential new therapeutic strategy for reducing atherosclerosis. Strategies for therapeutically raising LCAT activity include recombinant LCAT protein administration, viral expression of LCAT, and small molecule activators of LCAT [18].

\section{Method}

Preparation of aqueous extract of S. platensis

Spirulina platensis was produced and provided by an NGO named CAP-Spiruline situated at Nomayos (Yaounde- Cameroon).

Aqueous extract of $S$. platensis was obtained by macerating $100 \mathrm{~g}$ of $S$. platensis powder with $1000 \mathrm{~mL}$ of distilled water. This mixture was then placed on intermittent agitation for $24 \mathrm{~h}$, and the filtrate obtained was immediately lyophilized. The powder obtained was used for various studies. The extraction yield was $16.84 \%$ which was calculated using the following formula: $\mathrm{Rd}=$ Mass of the extract obtained $\times 100 /$ initial powder mass.

\section{Animal and toxicity material}

Before beginning the study, an ethical clearance was obtained ( $\mathrm{N}^{\circ}$ 2016/01/699/CE/CNERSH/SP).

S. platensis was prepared by dissolving $500 \mathrm{mg}$ of powder in $1 \mathrm{ml}$ of distilled water to obtain a stock solution of $500 \mathrm{mg} / \mathrm{ml}$.

Male and female Wistar rats around two months old and between 180 and $200 \mathrm{~g}$ of weigh were used in this study. They were all raised in physiological cage at the Faculty of Medicine and Biomedical Sciences of the University of Yaounde I. They had free access to water and food. The food composition include: carbohydrates (55\%), proteins (20\%), lipids (3.4\%), cellulose (1\%), minerals (4.9\%), vitamins (1.7\%) and moisture (14\%). The acute toxicity was determined according to the guideline 420 of the OECD [19]. A total of 20 rats divided into 2 groups of 10 rats for each group (5 males and 5 females) for the control and assay. The rats of the control groups received distilled water while those of the test group received a single dose $(5000 \mathrm{mg} / \mathrm{kg}$ of body weight) of $S$. platensis dissolved in distilled water. The volume administered at each rat was calculated according to the following formula: Volume $(\mathrm{ml})=[$ dose $(\mathrm{mg} / \mathrm{kg})^{*}$ weight $\left.(\mathrm{kg})\right] /$ concentration $(\mathrm{mg} / \mathrm{ml})$.

For sub-acute, the guideline 407 was used [20]. In this study, 40 rats were divided into 4 groups of 10 rats. A group 1 called control received distilled water. The other groups (2-4) received three different doses of S. platensis (250, 500 and $1000 \mathrm{mg} / \mathrm{kg}$ body weight).

The extract of $S$. platensis was administered through the orally by gavage using a needle once (acute toxicity) and daily up to 28 days (sub-acute toxicity).

After 28 days, the rats were sacrificed after anesthesia with ether; the blood was obtained by cervical dislocation and collected in dry tubes for the determination of biochemical parameters. These parameters included the investigation of urea, total cholesterol, triglycerides, high 
density lipoprotein cholesterol levels using enzymatic and colorimetric methods (CYPRESS, BELGIUM). The determination of creatinine concentration was carried out by the kinetic Jaffe method (CYPRESS, BELGIUM) while the activities of transaminases (AST and ALT) were performed with kinetic method (CYPRESS BELGIUM).

The activity of hydroxy methyl glutaryl coenzyme A reductase (HMG CoA reductase) was determined in the plasma, by spectrophotometric method as described in the kits (SIGMA ALDRICH, GERMANY). The assay is based on a spectrophotometric measurement of the decrease in absorbance at $340 \mathrm{~nm}$ which represents the oxydation of NADPH by the catalytic subunit of HMG CoA reductase in the presence of the substrate HMG $\mathrm{CoA}$. The results are expressed as UI/mg of protein.

The lecithine cholesterol acyl transferase (LCAT) activity was determined by a fluorimetric method using a kit (SIGMA ALDRICH, GERMANY). The fluorescence emission titration were recorded using an optic fiber spectrometer Avantes 2048 (Avantes, Netherlands), with spectral sensitivity within $250-1100 \mathrm{~nm}$ range. The LCAT Activity Assay Kit is a fluorometric assay useful for measuring the phospholipase activity of LCAT. We have to mix $1 \mathrm{~mL}$ of LCAT Substrate Reagent with $200 \mathrm{~mL}$ of Assay Buffer and LCAT source $(3-5 \mathrm{~mL}$ of plasma or serum). Then to incubate for $4-8 \mathrm{~h}$ at $37^{\circ} \mathrm{C}$. After what add $100 \mathrm{~mL}$ of the incubated mixture to $300 \mathrm{~mL}$ of Read Reagent and measure the fluorescent label ( $\mathrm{ex}=340 / \mathrm{em}=390$ and $470 \mathrm{~nm})$ and determine the plasmatic ratio ( em 470/ em 390).

\section{Histopathology study}

The sections of the liver and kidney were fixed in 10\% buffered formalin, dehydrated in ethanol, cleared in xylene, and embedded in paraffin. Fixed tissues were sectioned using a microtome. Then, these sections were stained with hematoxylin and eosin and were examined under the optic microscope for toxicant induced changes.

\section{Statistical analysis}

Results are expressed as Mean \pm SD of triplicate assays. The factor has been tested using Kruskal wallis test and
Dunnett's and Bonforroni multiple test helped for establishing difference between means. Ponderal growth as well as LCAT activity between male and female at each concentration were analyzed through independent sample T-test. The relationship between parameters was achieved with the Spearman rho Correlation Analysis. The differences were considered as significant at $P<0.05$. SPSS hardware, version 18.0 for Windows helped in analyzing data.

\section{Results}

Physical observations indicated no signs of changes in the skin, fur, eyes mucous membrane, behaviour patterns, tremors, salivation, and diarrhoea of the rats. There was neither mortality observed at the tested dose nor weight loss in the rats receiving S. platensis. The fifty percent lethal dose $\left(\mathrm{LD}_{50}\right)$ of $S$. Platensis extract was therefore estimated to be more than $5000 \mathrm{mg} / \mathrm{kg}$. We noted a significant $(p<0.05)$ weight gain in male rats ingesting $\mathrm{S}$. platensis compared to the control male group (Table 1). This difference was not significant in the group of female rats.

The Table 2 shows the results of lipid profile during subacute toxicity. The level of total cholesterol decreased in the male groups of rats treated with S. platensis compare with control; this reduction was only statistically significant at $500 \mathrm{mg} / \mathrm{kg}$. Regarding the level of HDL cholesterol, only the female group exhibited a significant decrease of concentration mainly at $1000 \mathrm{mg} / \mathrm{kg}$.

The effects of subacute administration of $S$. platensis extract on liver and kidney biochemical parameters are presented in Table 3. Most of these biochemical assays in treated rats were not significantly different from the controls, with the exception of albumin which was low at $500 \mathrm{mg} / \mathrm{kg}$.

Table 4 shows the variations of HMG CoA reductase activity in both groups of rats. In both male and female rats, we found inhibition of the enzyme in rats fed by $S$. platensis; this inhibition is dose-dependent, marked with a dose of $1000 \mathrm{mg} / \mathrm{kg}$. The difference between the groups is statistically significant $(p<0.05)$.

The variation in LCAT activity of the rats presented in the Fig. 1 shows that at the dose of $250 \mathrm{mg} / \mathrm{kg}$ bw, the level of LCAT was higher both in male and female

Table 1 Weight of the groups of rats

\begin{tabular}{|c|c|c|c|c|}
\hline \multirow[t]{2}{*}{ Days } & \multicolumn{4}{|c|}{ Weight of rats (Mean \pm SD) } \\
\hline & Control female & Test female & Control male & Test Male \\
\hline Day 1 & $117,60 \pm 10,784$ & $118,6 \pm 16,622$ & $117 \pm 14,832$ & $117,8 \pm 10,426$ \\
\hline Day 7 & $138,40 \pm 11,194$ & $146,00 \pm 20,261$ & $149,20 \pm 16,814$ & $161,60 \pm 9,503$ \\
\hline Day 14 & $144,00 \pm 8,031$ & $155,60 \pm 19,476$ & $167,20 \pm 17,669$ & $193,20 \pm 13,424$ \\
\hline $\begin{array}{l}\text { Mean weight gained } \\
\text { between day } 1 \text { and day } 14\end{array}$ & $26.4 \pm 15.59$ & $37 \pm 28.50$ & $50.2 \pm 22.12$ & $75.4 \pm 20.25$ \\
\hline$p$ value & $p>0.05$ & & $p<0.05$ & \\
\hline
\end{tabular}


Table 2 Lipid profile of female and male rats after 28 days of administration of S. platensis

\begin{tabular}{|c|c|c|c|c|c|c|c|c|}
\hline \multicolumn{5}{|l|}{ Females } & \multicolumn{4}{|l|}{ Males } \\
\hline $\begin{array}{l}\text { Doses } \\
\mathrm{mg} / \mathrm{kg} \text { bw }\end{array}$ & $\begin{array}{l}\mathrm{TC} \\
(\mathrm{mg} / \mathrm{dl})\end{array}$ & $\begin{array}{l}\mathrm{HDL} \mathrm{C} \\
(\mathrm{mg} / \mathrm{dl})\end{array}$ & $\begin{array}{l}\text { TG } \\
(\mathrm{mg} / \mathrm{dl})\end{array}$ & $\begin{array}{l}\text { Atherogenic index } \\
\mathrm{CT} / \mathrm{HDL} \mathrm{C}\end{array}$ & $\begin{array}{l}\text { TC } \\
(\mathrm{mg} / \mathrm{dl})\end{array}$ & $\begin{array}{l}\mathrm{HDL} \mathrm{C} \\
(\mathrm{mg} / \mathrm{dl})\end{array}$ & $\begin{array}{l}\text { TG } \\
(\mathrm{mg} / \mathrm{dl})\end{array}$ & $\begin{array}{l}\text { Atherogenic index } \\
\mathrm{CT} / \mathrm{HDL} \mathrm{C}\end{array}$ \\
\hline Control & $66 \pm 23$ & $42 \pm 7^{a}$ & $250 \pm 118$ & $1.64 \pm 0.42$ & $92 \pm 17^{a}$ & $52 \pm 6$ & $385 \pm 90$ & $1.76 \pm 0.14$ \\
\hline 250 & $62 \pm 12$ & $43 \pm 8^{a}$ & $257 \pm 98$ & $1.44 \pm 0.19$ & $84 \pm 9^{a}$ & $53 \pm 9$ & $294 \pm 147$ & $1.58 \pm 0.17$ \\
\hline 500 & $61 \pm 11$ & $40 \pm 8^{a}$ & $207 \pm 160$ & $1.50 \pm 0.10$ & $74 \pm 6^{b}$ & $40 \pm 3$ & $229 \pm 152$ & $1.85 \pm 0.32$ \\
\hline 1000 & $57 \pm 4$ & $35 \pm 5^{b}$ & $289 \pm 127$ & $1.62 \pm 0.19$ & $89 \pm 14^{a}$ & $49 \pm 3$ & $334 \pm 86$ & $1.81 \pm 0.19$ \\
\hline
\end{tabular}

In the same column, the values subscripted with the same letter are not significantly different at $p<0.05$

Bw body weight, TC total cholesterol, HDL C High Density Lipoprotein cholesterol, LDL C Low Density Lipoprotein cholesterol, TG Triglycerides

groups compared to control. However, this variation was not statistically significant within the groups $(p=0.399$ for males groups and $p=0.801$ for females groups). When comparing the sex, the level of LCAT was significantly higher in males compared to female except at $250 \mathrm{mg} / \mathrm{kg}$ [ $p=0.02$ (control); $p=0.07$ (250 mg/kg body weight); $p=0.003$ (500 mg/kg body weight); $p=0.04$ (1000 mg/kg body weight)].

Figure 2 shows the histopathological studies of livers and kidneys of the rats fed with $S$. platensis. We found the presence of an inflammatory granuloma especially at the doses 500 or $1000 \mathrm{mg} / \mathrm{kg}$ bw. This inflammation is the evidence of lymphocyte multiplication and is not accompanied by cytolysis. The kidney sections show chronic interstitial inflammatory infiltrate microfoci predominant around the tubules with mesangial hyperplasia especially at $250 \mathrm{mg} / \mathrm{kg}$ the female rats in particularly. However, at the highest dose, the histopathology of the kidneys is normal.

\section{Discussion}

Various herbs have been used as treatment and prevention for several chronic diseases such as diabetes, hypercholesterolemia and triglyceridemia. In screening natural products for the pharmacological activity, assessment and evaluation of the toxic characteristics of a natural product extract, fraction, or compound are usually an initial step. In our study we investigated the effects of aqueous extract of $S$. platensis on lipid profile mainly on the plasmatic activity of LCAT and HMG-CoA reductase after 28 days of toxicological studies.

Acute toxicity is defined as adverse effects occurring because of short-term administration of a single dose or multiple doses given within $24 \mathrm{~h}$ [21]. Acute toxicity tests give a quantitative estimation of acute toxicity, identify target organs and other clinical manifestations of acute toxicity and provide guidance for dose-ranging studies. This test is usually a valid predictor of the response seen in humans [18]. Indeed, the literature reports that the substances with $\mathrm{LD}_{50}$ higher than $5 \mathrm{~g} / \mathrm{kg}$ b.w., by oral route are regarded as being safe or practically non-toxic [22]. This is an indication that the aqueous solution of $S$. platensis has negligible level of toxicity when administered orally. At a dose of $5000 \mathrm{mg} /$ $\mathrm{kg}$, S. platensis showed no deaths of rats after acute toxicity. Also, the LD (lethal dose) value for phycocyanin a main active component of $\mathrm{S}$. platensis extract has been higher than $5000 \mathrm{mg} / \mathrm{kg}$ [23].

Furthermore, the diets and water were well-accepted by the rats treated with $S$. platensis extract suggesting the extract did not cause any alterations in carbohydrate, protein or fat metabolism in these experimental animals. Our results also showed that the $S$. platensis extract did not adversely interfere with the nutritional benefits, such as weight gain and stability of the appetite. The body

Table 3 Biochemical parameters of females and males rats after 28 days administration of Spirulina platensis

\begin{tabular}{lllllllll}
\hline & $\begin{array}{l}\text { DOSES } \\
\mathrm{mg} / \mathrm{kg} \mathrm{bw}\end{array}$ & $\begin{array}{l}\text { Alb } \\
(\mathrm{g} / \mathrm{l})\end{array}$ & $\begin{array}{l}\text { Urea } \\
(\mathrm{g} / \mathrm{l})\end{array}$ & $\begin{array}{l}\text { Creatinine } \\
(\mathrm{mg} / \mathrm{l})\end{array}$ & $\begin{array}{l}\text { AST } \\
(\mathrm{Ul} / \mathrm{l})\end{array}$ & $\begin{array}{l}\text { ALT } \\
(\mathrm{U} / \mathrm{l})\end{array}$ & $\begin{array}{l}\text { T Bili } \\
(\mathrm{mg} / \mathrm{l})\end{array}$ & $\begin{array}{l}\mathrm{D} \text { Bili } \\
\mathrm{mg} / \mathrm{l}\end{array}$ \\
\hline Females & Control & $34.75 \pm 1.29$ & $0.59 \pm 0.06$ & $9.94 \pm 1.33$ & $295.93 \pm 32.85$ & $64.11 \pm 7.23$ & $1.23 \pm 0.48$ & $0.43 \pm 0.31$ \\
& 250 & $35.65 \pm 1.41$ & $0.53 \pm 0.05$ & $9.04 \pm 0.57$ & $324.05 \pm 78.35$ & $71.71 \pm 20.47$ & $1.34 \pm 0.36$ & $0.39 \pm 0.19$ \\
& 500 & $33.933 .98 \pm 2.63$ & $0.62 \pm 0.12$ & $8.65 \pm 1.59$ & $288.70 \pm 58.60$ & $68.54 \pm 23.08$ & $0.95 \pm 0.22$ & $0.32 \pm 0.14$ \\
& 1000 & $35.01 \pm 0.75$ & $0.53 \pm 0.10$ & $9.96 \pm 1.08$ & $379.43 \pm 126.9$ & $77.17 \pm 19.96$ & $1.48 \pm 0.26$ & $0.55 \pm 0.07$ \\
Males & Control & $34.23 \pm 0.94^{\mathrm{a}}$ & $0.62 \pm 0.24$ & $8.97 \pm 1.75$ & $344.75 \pm 136.46$ & $91.58 \pm 37.29$ & $1.07 \pm 0.20$ & $0.42 \pm 0.19$ \\
& 250 & $36.31 \pm 0.82^{\mathrm{ab}}$ & $0.56 \pm 0.21$ & $9.30 \pm 0.76$ & $337.78 \pm 125.44$ & $80.32 \pm 18.59$ & $1.26 \pm 0.38$ & $0.52 \pm 0.42$ \\
& 500 & $31.07 \pm 2.42^{\mathrm{c}}$ & $0.62 \pm 0.14$ & $9.24 \pm 0.67$ & $291.90 \pm 22.72$ & $112.39 \pm 33.07$ & $1.14 \pm 0.41$ & $0.51 \pm 0.19$ \\
& 1000 & $34.58 \pm 0.62^{\mathrm{a}}$ & $0.61 \pm 0.07$ & $9.02 \pm 0.33$ & $357.86 \pm 75.02$ & $102.29 \pm 16.56$ & $1.25 \pm 0.26$ & $0.46 \pm 0.15$ \\
\hline
\end{tabular}

In the same column, the values subscripted with the same letter are not significantly different at $p<0.05$

Bw body weight, AST Aspartate Amino transferase, ALT Alanine Amino Transferase, $T$ Bili total bilirubin, D Bili direct bilirubin, Alb albumin 
Table 4 Activity of HMG CoA reductase of males and females rats after 28 days administration of Spirulina platensis

\begin{tabular}{lcc}
\hline Groups & \multicolumn{2}{c}{ HMG CoA reductase activity (UI/mg protein) } \\
\cline { 2 - 3 } & Rats Males & Rats Females \\
\hline control & $0.38 \pm 0.001^{\mathrm{a}}$ & $13.45 \pm 0.002^{\mathrm{a}}$ \\
$250 \mathrm{mg} / \mathrm{kg}$ & $0.13 \pm 0.002^{\mathrm{b}}$ & $3.99 \pm 0.000^{\mathrm{b}}$ \\
$500 \mathrm{mg} / \mathrm{kg}$ & $0.06 \pm 0.000^{\mathrm{c}}$ & $5.07 \pm 0.007^{\mathrm{c}}$ \\
$1000 \mathrm{mg} / \mathrm{kg}$ & $0.02 \pm 0.000^{\mathrm{d}}$ & $0.50 \pm 0.000^{\mathrm{d}}$ \\
\hline
\end{tabular}

In the same column, the values subscripted with the same letter are not significantly different at $p<0.05$

weight changes serve as a sensitive indication of the general health status of animals [24].

Subchronic toxicity studies on $S$. platensis have been conducted by some researchers [21]. Our toxicological study brings some differences, mainly in the feeds given to the animals, the time of administration, and the kind of analysis conducted. The exploration of liver and kidney function is very important in the investigation of toxicity of drugs and plant extracts as they are both necessary for the survival of an organism [25]. High levels of ALT, AST, and alkaline phosphatase (ALP) are reported in liver diseases or hepatotoxicity [26]. No significant changes was found in ALT, AST, in our study in both male and female rats at all doses suggesting that the administration of $S$. platensis extract does not affect the hepatocyte function in the rats. In a chemopreventive study of S. platensis against deltamethrin, Abdel-Daim and al [27] observed a reduction of hepatic markers (transaminases, alkaline phosphatase, bilirubin, total cholesterol) and renal markers (urea, creatinine, uric acid). The liver sections revealed significant lymphocytic multiplication. Previous studies showed the hepatoprotective effects of $S$. platensis and its active constituents against drugs, chemicals and xenobiotics [28-30].

The protective role of $S$. platensis could be attributed to the presence of $ß$-carotene, superoxide dismutase, selenium and blue pigment phycocyanin in the algae [5]. Phycocyanin significantly reduced the hepatotoxicity caused by paracetamol which induces the formation of free radicals. The hepatoprotective effect of phycocyanin was therefore attributed to the inhibition of reaction involved in the formation of reactive metabolites and possibly due to its radical scavenging activity. Also, a study has revealed that the hepatoprotective mechanism of S. platensis passes through the presence of phycocyanin and is related to the blockage of inflammatory infiltration by inhibiting the expression of tumor growth factor-beta 1 and hepatocyte growth factor [31, 32].

Our study demonstrated no changes in plasma urea and creatinine levels in S. platensis extract treated groups indicating a normal renal function. The nephroprotective effects of $S$. platensis have been reported against renal injury induced by gentamicin [33] as well as oxalate [34]. The effective compound responsible for the suppression of renal toxicity seems to be phycocyanin [35].

Changes in the parameters of the lipid profile between different groups of rats were not significant, except for cholesterol.

Cholesterol reduction and related effects of $S$. platensis have been reported mostly in subjects with elevated blood lipid levels [36]. It has been shown that administration of Arthrospira maxima (specie of Spirulina) associated with simvastatin prevents the acute fatty liver

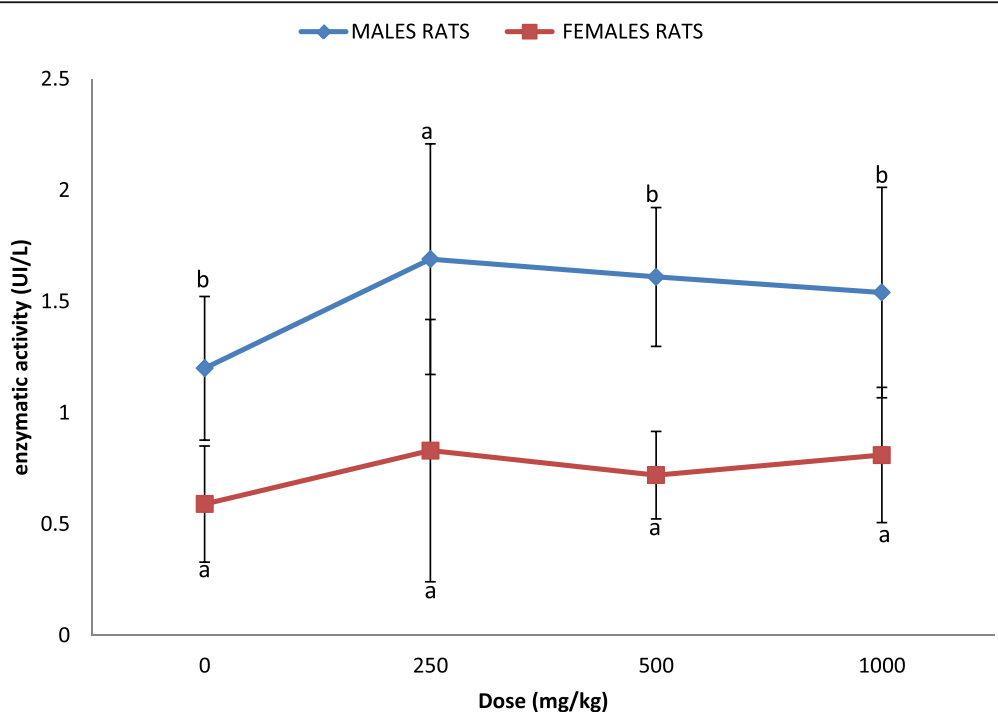

Fig. 1 Variation of LCAT activity of male and female rats after 28 days administration of Spirulina platensis. The values subscripted with the same letter are not significantly different at $p<0.05$ 


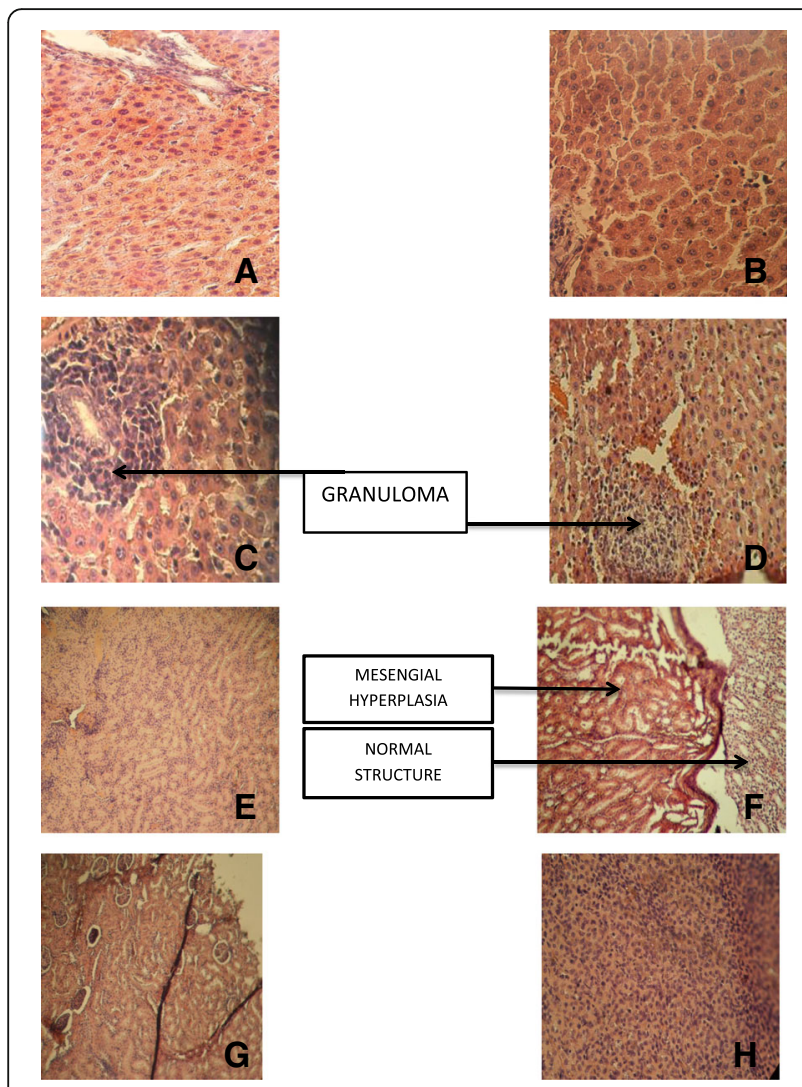

Fig. 2 Histopathology of the liver; hematoxylin and eosin X40. (a) control (b) $250 \mathrm{mg} / \mathrm{kg} \mathrm{bw} \mathrm{(c)} 500 \mathrm{mg} / \mathrm{kg} \mathrm{bw} \mathrm{(d)} 1000 \mathrm{mg} / \mathrm{kg} \mathrm{bw}$. (b) Histopathology of the kidney; hematoxylin and eosin X10. (e) control (f) $250 \mathrm{mg} / \mathrm{kg}$ bw (g) $500 \mathrm{mg} / \mathrm{kg}$ bw (h) $1000 \mathrm{mg} / \mathrm{kg}$ bw

induced by the administration of ethanol and a hypercholesterolemic diet to mice [37].

The hypocholesterolemic effects of Arthrospira maxima are in accordance with other reports on rats when it was given in a normal diet [38] with a highfructose diet [39] or when Arthrospira maxima was administered to humans, $4.2 \mathrm{~g} /$ day during 4 weeks [13]. Hyperlipidemia lowering effect of S. platensis seems to be more sensitive in an experimental model than in a normal blood lipid range [40].

The cholesterol homeostasis is very important for the human health. HMG COA reductase is the rate-limiting step in the biosynthesis of cholesterol in humans: it converts HMG COA into mevalonate. The inhibition of this enzyme would be an effective means of lowering plasma cholesterol. It has been suggested that exogenous cholesterol inhibits the expression of mRNA for of 3hydroxy-3-methyl coenzyme A reductase (HMG CoA reductase) $[39,41]$ that appears after the intracellular mevalonate deficit in the liver. The inhibition of HMG CoA reductase produces a depletion of the mevalonate metabolites which is critical for cellular viability $[24,42]$. Regulation of HMG CoA reductase activity is the primary approach for controlling de novo cholesterol synthesis, while abnormal activation can lead to hepatic cholesterol accumulation and hypercholesterolemia. Full suppression of the reductase requires the presence of at least two regulators: cholesterol, which is normally derived exogenously from plasma low density lipoprotein (LDL), and a non-sterol product, which is normally synthesized endogenously from mevalonate [16]. The major metabolic pathway for reducing cholesterol is via conversion to bile acids or preventing the cholesterol synthesis by inhibiting the HMG CoA reductase enzyme. In our study, we found that the decrease of plasmatic HMG COA reductase in the plasma of the treated group was between 2.9 and 26.9 fold higher compared to control. Moreover, the ratio between HMG CoA reductase of the female and male rats varied from 25 to 84.5 with the maximum at the dose of $250 \mathrm{mg} / \mathrm{kg}$ bw. These results confirmed that the administration of S. platensis inhibits the plasmatic activity of HMG COA reductase significantly in the male than the female rats. The enzyme inhibitory effect correlates with the medicinal properties and phytochemical components of S. platensis such as phenol and flavonoids compounds. Some studies have also reported the ex vivo inhibition of HMG CoA reductase activity by herbs specially medicinal plants, namely, Quercus infectoria, Rosa damascene, Myrtus communis, Andrographis paniculata, Anthocephalus indicus, and Ocimum sanctum [16, 17]. Clinical trials have shown that the use of HMG CoA reductase inhibitors in patients with coronary risk improved endothelial function through reduction of oxidative stress and/or up regulation of NO activity [43].

Lecithin cholesterol acyltransferase (LCAT) is one of the major modulators of plasma high-density lipoprotein cholesterol (HDL-C) and plays a central role in the reverse cholesterol transport (RCT) process [44]. LCAT is a plasma enzyme that circulates mostly in association with the high density lipoproteins (HDL) and is responsible for the synthesis of cholesterol esters present in human plasma. Cholesterol esterification catalyzed by LCAT also reduces the amount of unesterified cholesterol in plasma. The level the highest level of LCAT was noted at $250 \mathrm{mg} / \mathrm{kg}$ bw demonstrating the increase of esterification of cholesterol which lead to the synthesis of HDL-C. These findings corroborate with the higher concentration of HDL-C noted in the group of rats receiving $250 \mathrm{mg} / \mathrm{kg}$ of $S$. platensis extract. Therefore LCAT plays a key role in the incorporation of free cholesterol into HDL and its transfer back to VLDL and LDL, which are later returned in liver cells [45]. Our study has shown that the synergistic effect of HMG CoA reductase inhibition and LCAT activation reduced the level of cholesterol in the group of rats treated with $S$. platensis. 


\section{Conclusions}

Administration of aqueous extract of S. platensis from Nomayos in Cameroon resulted in little toxic effects. It demonstrates hypolipidemic activity through an activation of LCAT. The findings provide preliminary data that suggest that $S$. platensis is capable of reducing total cholesterol. Further studies are needed to confirm this result by inducing hypercholesteromia.

\section{Abbreviations}

Dw: Dry weight; HDL: High Density Lipoproteins; HIV: Human Immunodeficiency Virus; HMG CoA reductase: Hydroxy Methyl Glutaryl Coenzyme A Reductase; LCAT: Lecithine Cholesterol Acyltranferase; LD: lethal dose; LDL: Low Density Lipoproteins; NGO: Non-Governmental Organization; OECD: Organization for Economic Cooperation and Development

\section{Acknowledgements}

The authors thank the pharmaceutical students who helped for sacrifiying the animals and Dr. Tatah A. Sandra for helping us to edit this article.

\section{Funding}

This research doesn't receive fund from organization. All the authors contribute to buy reagents.

\section{Availability of data and materials}

Available from the authors.

\section{Authors' contributions}

VJAM, CAP, JN initiated the project. BLNN raised animals and sacrificed them. VJAM, CAP, BMM conducted biological tests. ZS carried out the histopathological analysis. PCNB conducted statistical analyzes. KC and AB and VJAM conducted analyzes by fluorimetry. MENM provided spirulina. VJAM, CAP, PCNB, MDB, BLNN, MENM, JN wrote, corrected the manuscript. JN supervised the study. All the authors read and approved the final manuscript.

\section{Competing interests}

The authors declare that they have no competing interests.

\section{Consent for publication}

Not applicable.

\section{Ethical approval}

This study was undertaken in accordance with the University guidelines for the care and use of laboratory animals.

National committee on ethics and research of Cameroon: Ethical clearance $N^{\circ}$ 2016/01/699/CE/CNERSH/SP.

\section{Publisher's Note}

Springer Nature remains neutral with regard to jurisdictional claims in published maps and institutional affiliations.

\section{Author details \\ ${ }^{1}$ Department Physiological Sciences and Biochemistry, Faculty of Medicine and Biomedical Sciences - University of Yaounde 1, Yaounde, Cameroon. ${ }^{2}$ Department of Biochemistry, Faculty of Sciences, University of Dschang, Dschang, Cameroon. ${ }^{3}$ Department of Pharmarcy and Traditional Medicine, Faculty of Medicine and Biomedical Sciences, University of Yaoundé I, Yaounde, Cameroon. ${ }^{4}$ Department of Physics, Cepamoq, University of Douala, Douala, Cameroon. ${ }^{5}$ Department of Biochemistry, Faculty of Sciences, University of Ngaoundere, Ngaoundere, Cameroon.}

\section{Received: 17 November 2016 Accepted: 8 March 2017} Published online: 14 March 2017

\section{References}

1. Sapp J. The prokaryote-eukaryote dichotomy: meanings and mythology. Microbiol Mol Biol Rev. 2005;69:292-305.
2. Vonshak A. Spirulina platensis (Arthrospira): physiology, cell-biology and biotechnology. London: Taylor \& Francis; 1997. p. 43-66.

3. Gershwin ME, Belay A, editors. Spirulina in human nutrition and health. Boca Raton: CRC Press; 2008.

4. Barry M, Ouedraogo M, Sourabie S, Guissou IP. Intérêt thérapeutique de la spiruline chez I'homme: revue général. Int J Biol Chem Sci. 2014;8(6):2740-9.

5. Bhat VB, Madyastha M. Scavenging of peroxynitrite by phycocyanin and phycocyanobilin from Spirulina platensis: protection against oxidative damage to DNA. Biochem Biophys Res Commun. 2001;285:262-6.

6. Svcerk C. Cyanobacteria toxins and the current state of knowledge on water treatment option: a review. J Environ Eng Sci. 2004;3:155-84.

7. Fox RD. Spirulina: production and potential. Aix-en-Provence: Edisud; 1996.

8. Ngo-Matip ME, Pieme CA, Azabji-Kenfack M, Moukette Moukette B, Korosky E, Stefanini P, Yonkeu Ngogang J, Mbofung CM. Impact of daily supplementation of Spirulina platensis on the immune system of naïve HIV1 patients in Cameroon: a 12-months single blind, randomized, multicenter trial. Nutr J. 2015;14:70

9. Deng $\mathrm{R}$, Chow TJ. Hypolipidemic, antioxidant and antiinflammatory activities of microalgae Spirulina. Cardiovasc Ther. 2010;28(4):e33-45.

10. Devi MA, Venkataraman LV. Hypocholesterolemic effect of blue-green algae Spirulina platensis in albino rats. Ann Nutr Reports Int. 1983;28:519-30.

11. Kato T, Takemoto K, Katayama H, Kuwabara Y. Effects of Spirulina (Spirulina platensis) on dietary hypercholesterolemia in rats. J Jpn Soc Nutr Food Sci. 1984:37:323-32.

12. El-Sheekh M, Hamad SM, Gomaa M. Protective Effects of Spirulina on the Liver Function and Hyperlipidemia of Rats and Human. Braz Arch Biol Technol. 2014;57(1):77-86

13. Nakaya N, Homma Y, Goto Y. Cholesterol lowering effect of Spirulina. Nutr Rep Int. 1988;37:1329-37.

14. Ramamurthy A, Premakumari S. Effect of supplementation of Spirulina on hypercholesterolemic patients. J Food Sci Technol. 1996;33(2):124-8.

15. Ngo-Matip ME, Pieme AC, Azabji-Kenfack M, Nya Biap PC, Nkenfack G, Heike E, Moukette Moukette B, Korosky E, Mbofung CM, Yonkeu Ngogang J. Effects of Spirulina platensis supplementation on lipid profile in HIVinfected antiretroviral naïve patients in Yaounde - Cameroon: a randomized trial study. Lipids Health Dis. 2014;13:191.

16. Vanitha RP, Asna U. Inhibition of 3-Hydroxy-3-methylglutaryl Coenzyme A Reductase (Ex Vivo) by Morus indica (Mulberry). Chin J Biol. 2014;5. Article ID 318561. doi:10.1155/2014/318561.

17. Patel HD, Shah GB, Trivedi V. Investigation of HMG CoA reductase inhibitory activity of antihyperlipidemic herbal drugs in vitro study. Asian J Exp Biol and Sci. 2011;2:63-8.

18. Chen Z, Wang SP, Krsmanovic ML, Castro-Perez J, Gagen K, Mendoza V, Rosa R, Shah V, He T, Tout SJ, Geoghagen NS, Lee SH, McLaren DG, Wang L, Roddy TP, Plump AS, Hubbard BK, Sinz CJ, Johns DG. Small molecule activation of lecithin cholesterol acyltransferase lipoprotein metabolism in mice and hamsters. Metabolism. 2012;61:470-81

19. OCDE. Lignes directrices de l'OCDE pour les essais de Produits chimiques: étude de toxicité orale à dose répétée pendant 28 jours sur les rongeurs. 2008

20. OCDE. Ligne directrice de l'OCDE pour les essais de produits chimiques: toxicité orale aiguë - Méthode de la dose prédéterminée. 2001

21. Chinedu E, Arome D, Ameh FS. A new method for determining acute toxicity in animals models. Toxicol Int. 2013;20(3):224-6.

22. Kennedy GL, Ferenz RLJ, Burgess BA. Estimation of acute toxicity in rats by determination of the approximate lethal dose rather than the LD50. J Applied Toxicol. 1986;6:145-8.

23. Naidu KA. Toxicity assessment of phycocyanin-a blue colorant from bluegreen alga Spirulina platensis. Food Biotechnol. 1999;13:51.

24. El Hilaly J, Israili H, Lyoussi B. Acute and chronic toxicological studies of Ajuga iva in experimental animals. J Ethnopharmacol. 2004;91(1):43-50.

25. Karadeniz A, Cemek M, Simsek N. The effects of Panax ginseng and Spirulina platensis on hepatotoxicity induced by cadmium in rats. Ecotoxicol Environ Saf. 2009;72:231-5

26. Hussein RRS, Soliman RH, Abdelhaleem Ali AM, Tawfeik MH, Abdelrahim MEA. Effect of antiepileptic drugs on liver enzymes. Beni-Suef University. J Basic Appl Sci. 2013;2(1):14-9.

27. Abdel-Daim MM, Abuzead SMM, Halawa SM. Protective role of spirulina platensis against acute deltamethrin-induced toxicity in rats. PLoS One. 2013;8(9):e72991. 
28. Tsai YC, Leichner GS, Pearce MMP, Wilson GL, Wojcikiewicz RJH, Roitelman J, Weissman AM. Differential regulation of HMG-CoA reductase and Insig-1 by enzymes of the ubiquitin-proteasome system. Mol Biol Cell. 2012;23(23):4484-94.

29. Ismail MF, Ali DA, Fernando A, Abdraboh ME, Gaur RL, et al.

Chemoprevention of rat liver toxicity and carcinogenesis by Spirulina. Int $J$ Biol Sci. 2009;5:377-87.

30. Vadiraja BB, Gaikwad NW, Madyastha KM. Hepatoprotective effect of Cphycocyanin: protection for carbon tetrachloride and R-

(+)-pulegonemediated hepatotoxicty in rats. Biochem Biophys Res Commun. 1998;249:428-31.

31. Ou Y, Zheng S, Lin L, Jiang Q, Yang X. Protective effect of C-phycocyanin against carbon tetrachloride-induced hepatocyte damage in vitro and in vivo. Chem Biol Interact. 2010;185(2):94-100.

32. Ming-Jyh S, Yao-Yuan H, Ching-Hsiu L, Chi-Chen C, Chieh-Hsi W Antihyperlipidemic and antioxidant effects of C-phycocyanin in Golden Syrian Hamsters fed with a hypercholesterolemic diet. J Tradit Complement Med. 2013:3(1):41-7.

33. Karadeniz A, Yildirim A, Simsek N, Kalkan Y, Celebi F. Spirulina platensis protects against gentamicin-induced nephrotoxicity in rats. Phytother Res. 2008;22:1506-10

34. Faroog SM, Asokan D, Kalaiselvi P, Sakthivel R, Varalakshmi P. Prophylactic role of phycocyanin: a study of oxalate mediated renal cell injury. Chem Biol Interact. 2004;149:1-7.

35. Fukino $\mathrm{H}$, et al. Effect of Spirulina on the renal toxicity induced by inorganic mercury and cisplatin. Eisei Kagaku. 1990;36:5.

36. Belay A. The Potential Application of Spirulina (Arthrospira) as a Nutritional and Therapeutic Supplement in Health Management. JANA. 2002;5(2):26-48.

37. Ble-Castillo JL, Rodriguez-Hernandez A, Miranda-Zamora R, Juarez-Oropeza MA, Diaz-Zagoya JC. Arthrospira maxima prevents the acute fatty liver induced by the administration of simvastatin, ethanol and a hypercholesterolemic diet to mice. Life Sci. 2002;70:2665-73.

38. Iwata K, Inayama T, Kato T. Effects of Spirulina platensis on fructose-induced hyperlipidemia in rats. J Jpn Soc Nutr Food Sci. 1987;40:463-7.

39. Gotto AM. Statin therapy: Where are we? Where do we go next? Am J Cardiol. 2001:87(5A):13B-8

40. Nongporn HT, Wantana R, Siva S, Pharkphoom P, Pratum R. A Subchronic Toxicity Study of Spirulina platensis. Food Sci Technol Res. 2008;14(4):351-8.

41. Toews AD, Jurevics $H$, Hostettler J, Roe EB, Morell P. Tissue-specific coordinate regulation of enzymes of cholesterol biosynthesis: sciatic nerve versus liver. J Lipid Res. 1996;37(12):2502-9.

42. Coleman PS, Chen LC, Sepp-Loprenzino L. Cholesterol metabolism and tumor proliferation. In: Bittman R, editor. Subcellular Biochemistry, vol. 28. Cholesterol: Its functions and metabolism in biology and medicine. New York: Plenum Press; 1997. p. 363-434.

43. Hadi HAR, Carr SC, Al SJ. Endothelial dysfunction: cardiovascular risk factors, therapy, and outcome. Vasc Health Risk Manag. 2005;1(3):183-98.

44. Dominic SNG. In: Cheema SK, editor. Biochemistry of Atherosclerosis edited by. New York: Springer; 2006

45. Dobiásová M, Frohlich J. Advances in understanding of the role of lecithin cholesterol acyltransferase (LCAT) in cholesterol transport. Clin Chim Acta. 1999;286:257-71.

\section{Submit your next manuscript to BioMed Central and we will help you at every step:}

- We accept pre-submission inquiries

- Our selector tool helps you to find the most relevant journal

- We provide round the clock customer support

- Convenient online submission

- Thorough peer review

- Inclusion in PubMed and all major indexing services

- Maximum visibility for your research

Submit your manuscript at www.biomedcentral.com/submit 